\title{
Influence of social relations on knowledge conflicts-An empirical study from Chinese universities
}

\author{
Huimin Liu ${ }^{1, *}$, Xiaofeng Dong ${ }^{2}$ \\ 1, 2 Nanjing University, China
}

\section{Keywords:}

Relation model

Research team

Knowledge sharing

Knowledge conflicts

Received: 31 October 2015

Accepted: 16 January 2016

Published: 22 February 2016

\begin{abstract}
This paper aims to systematically investigate the impact of different types of social relationships on knowledge conflicts during the process of knowledge sharing based on the theory of relation model. This empirical study collected 288 surveys from research team members in fourteen universities in China. The results show that public sharing and academic power have positive effects on cognitive knowledge conflicts and negative effects on emotional knowledge conflicts; expected association has more significant effects on knowledge conflicts than expected reward; sharing cost has positive effects on knowledge conflict, knowledge sharing willingness plays a mediating role between social relations and knowledge conflicts. At last, the paper presents management suggestions from perspectives of team trust, power allocation and incentive methods.
\end{abstract}

(C) 2016 The Author(s). Published by TAF Publishing.

\section{INTRODUCTION}

Research teams are a type of teams that adopt the manner of knowledge sharing and communication and take knowledge innovation as the purpose. Scientific research usually involves amount of implicit knowledge with strong theoretical and technical properties. Moreover, knowledge sharing in it is not simple knowledge exchange between individuals, but requires sharing parties to reprocess and recreate knowledge through joint efforts to realize knowledge transfer. During the above process, knowledge conflicts may be caused due to difference in knowledge structure and knowledge stock of both parties. Considering that the trans-disciplinary scientific research cooperation gradually becomes the main mode of scientific research innovation, knowledge conflicts caused by

\footnotetext{
*Corresponding author: Huimin Liu

E-mail: Liuhm@nju.edu.cn
}

knowledge heterogeneity also become the main challenge and issue faced by the scientific research team in knowledge sharing and innovation.

\section{LITERATURE REVIEW}

In recent years, scholars mostly studied knowledge conflicts from the view of combining knowledge management and conflict management and obtained fruitful research achievements, in which, the dichotomy that divides knowledge conflicts into cognitive conflicts and emotional conflicts was applied most widely (Tan et al., 2005). Cognitive conflicts are caused due to inconsistent views and opinions of team members in tasks, and emotional conflicts refer to the tension, friction and contradictions among members which are divided into the business part, such as the mutual dislike, and the feeling part, such as annoyance, depression and anger of oneself. The existing researches mainly focus on the influence relationship between knowledge conflicts and the team 
performance (Amason \& Schweiger, 1994) or take the knowledge conflicts as the intermediate variable for research of the team characteristics and the team performance (Zhang \& Fang, 2007) or focus on the adjustment function of certain variables in the relationship between knowledge conflicts and the team performance Yin (2012). Most of the above researches were always started with the influence effect of knowledge conflicts, while reasons for generating these conflicts were neglected. Especially researches related to occurrence mechanism of knowledge conflicts affected by interpersonal relations and social relations of the team members are quite few. In addition, studies on the influence of the team member relationship on knowledge sharing or knowledge innovation are relatively mature, but mostly focus on single dimension of trust factor, reciprocal psychology and other motivational factors (Li, Zhou \& Cai, 2010) and are short of systematism. The relational model theory, proposed by Fiske (1992) is a sort of theory that systematically and completely describes relations among the team members, whose fundamental hypothesis is that the cluster living style makes people organize their life from the view of the society and then social relations are generated. According to Fiske's (1992) relation model theory, the interpersonal sociability includes four aspects fundamentally, namely public sharing, authority ranking, equal matching and market pricing, which decide the way of people to communicate and interact with others. Boer and others firstly proposed the theory frame that the relational model theory could be applied to study knowledge sharing behavior (Boer, Hans \& Van Baalen, 2011). Based on this Lin, Wu \& Lu (2012) explored the influence factors of knowledge sharing willingness from the view of the relational model through the empirical research on personnel from all walks of life in Taiwan. Thus it can be seen that the research on knowledge sharing issue through the relational model theory is still at the preliminary stage. Based on the predecessors' researches, this paper takes knowledge sharing of the scientific research team as the research object and aims at systematic research on the influence of different social relations on knowledge sharing willingness and knowledge conflicts based on the relational model theory.

\section{RESEARCH MODEL}

Public Sharing, Knowledge Sharing Willingness and Knowledge Conflicts

Under the relation of public sharing, all team members are characterized by spontaneity, altruism, enthusiasm and have intense intention to share knowledge, not desiring any return and are free from potential purposes (Nonaka, Toyama \& Konno, 2000). Under this state, they fully trust each other and have strong sense of belonging in the team. According to the previous researches, trust and altruism are the main influence factors under the public sharing relation (Kurz, 1997).

Trust relies on sufficient understanding of others and members under the trust relation usually believe that the future behavior of others can be predicted, which consists of the basis of trust and then results in the expected share behavior (French, Raven \& Cartwright, 1959). Altruism is a kind of behavior of initiative provision of commodities and service for others without desire for any return Li (2008). Considering under the public sharing relation, each member of a team has strong sense of belonging in the team and is willing to make their own contribution to other team members, the knowledge sharing willingness of the team members is usually relatively intense; meanwhile, relatively active and open team communication will occur during the knowledge sharing process, which may possibly stimulate cognitive knowledge conflicts caused by different views, and under the public sharing relation, because team members tend to consider for and fully trust others, emotional knowledge conflicts caused by strained and inharmonious relations between team members are quite difficult to occur. Therefore, the following hypotheses can be concluded:

H1a: Public sharing has significant positive effect on knowledge sharing willingness.

H1b: Public sharing has significant positive effect on cognitive knowledge conflicts.

H1c: Public sharing has significant negative effect on emotional knowledge conflicts.

\section{Authority Ranking, Knowledge Sharing Willingness and Knowledge Conflicts}

Under the relation of authority ranking, the members in the team shall be ranked from the high position to the low position according to certain indexes and those who rank higher will own larger power, higher status and more words of power (Wei \& Long, 2011). Power in the scientific research team is usually composed of academic power and administrative power (Tang, 2000) different from government offices and ordinary enterprises, influence of the administrative power on the scientific research team is relatively weak, while the academic 
authority with relatively high academic power has the leading effect on knowledge sharing and knowledge innovation of the team. In addition, the power distance is often used to measure the hierarchical difference in the team (Blau, 1964).

If the power distance is relatively large, considering members with relatively large power and large legal force may forcibly require ones ranking low to share their knowledge, instead, it will suppress intention of members to initiatively share knowledge. Once there is difference in views of low-level members and high-level ones, the final consensus is usually reached through compromise of lowlevel ones. Therefore, cognitive knowledge conflicts will not be caused, but anxiety and discontent of low-level members may be triggered, which will further stimulate emotional knowledge conflicts. On the contrary, in a team where the authority ranking relation is weak, members tend to initiatively communicate, discuss and share with others. Therefore, the following hypotheses can be concluded:

H2a: Authority ranking has significant negative effect on knowledge sharing willingness.

H2b: Authority ranking has significant negative effect on cognitive knowledge conflicts.

H2c: Authority ranking has significant positive effect on emotional knowledge conflicts.

\section{Equal Matching, Knowledge Conflicts and Knowledge Sharing Willingness}

Under the equal matching relation, motivation for knowledge exchange among team members is the expectation of the predictable proper rewards. Based on the reciprocal psychology, in order to achieve the specific return, A is willing to initiatively share knowledge with $\mathrm{B}$ equal to A (Davenport \& Klahr, 1998). Here, return of A is the predicted future rewards, which include tangible economic rewards, and may include other intangible incentive forms.

In a scientific research team, besides the expected economic rewards that may be achieved through knowledge sharing, high-level scientific research achievements may also be achieved through transdiscipline, trans-faculty, trans-university, and even internationalized association to conduct high-level scientific research cooperation and innovation.

This is the return caused by the expected association (Joseph \& Jacob, 2011) in the scientific research team. Such an expectation of the reliable future return will facilitate team members' intention to share knowledge and accelerate information exchange in this team. Meanwhile, under this relation, team members stick to the concepts of fair exchange and cooperation. Therefore, as long as they believe the expected return is reliable, cooperation and exchange among them will be harmonious. Moreover, on one hand, motivation of one team member to share knowledge is paid; on the other hand, relations in the temporary team established through external association are loose and therefore, it is difficult to generate cognitive knowledge conflicts due to deep knowledge communication and emotional knowledge conflicts due to worsening of relations among team members. Therefore, the following hypotheses can be concluded:

H3a: Equal matching has significant positive effect on the knowledge sharing willingness.

H3b: Equal matching has significant negative effect on cognitive knowledge conflicts.

H3c: Equal matching has significant negative effect on emotional knowledge conflicts.

\section{Market Pricing, Knowledge Conflicts and Knowledge Sharing Willingness}

In the market pricing relation model, team members will neglect all other factors and consider the knowledge sharing behavior from the single tangible value (Lin, 2007). Here the tangible value is mainly realized through monetary compensation. Different from the expected future rewards in the equal matching relation, the monetary compensation here exists virtually. Under this relation, knowledge is regarded as a valuable commodity and can be traded with certain award amount. Theoretically, the manner that makes monetary compensation for the knowledge sharing behavior will strengthen member's intention to share knowledge and meanwhile, when members are aware of mismatching between costs and returns, which means knowledge sharing will consume a large amount of time and energy, tendency to share knowledge will be reduced. The theoretical basis of the market pricing relation is the transaction costs theory. Under the hypothesis of maximization of individual utility, with higher rate of return for the input, the intention to share knowledge will be stronger. During this process, as long as members think reliably for rewards of knowledge transactions, the possibility to generate knowledge conflicts is not high. Therefore, the following hypotheses can be concluded:

H4a: Market pricing has significant influence on 
knowledge sharing willingness.

H4b: Market pricing has significant influence on cognitive knowledge conflicts.

H4c: Market pricing has significant influence on emotional knowledge conflicts.

\section{Knowledge Sharing Willingness and Knowledge Conflicts}

The team knowledge sharing willingness refers to the degree to which an individual subjectively thinks initiatively and willingly shares its own knowledge with others (Lewis \& Weigert, 1985). In general, the stronger the knowledge sharing willingness in a team is, the more open is the communication among team members, the more intensive is the collision between views and knowledge (Hung et al., 2011) and the higher is the possibility of occurring of cognitive knowledge conflicts. Meanwhile, as the members' knowledge sharing is from their own initiative intention, emotional conflicts triggered due to anxiety and discontent will not occur. Therefore, the following hypotheses can be concluded:

H5a: knowledge sharing willingness has significant positive effect on cognitive knowledge conflicts

H5b: knowledge sharing willingness has significant negative effect on emotional knowledge conflicts

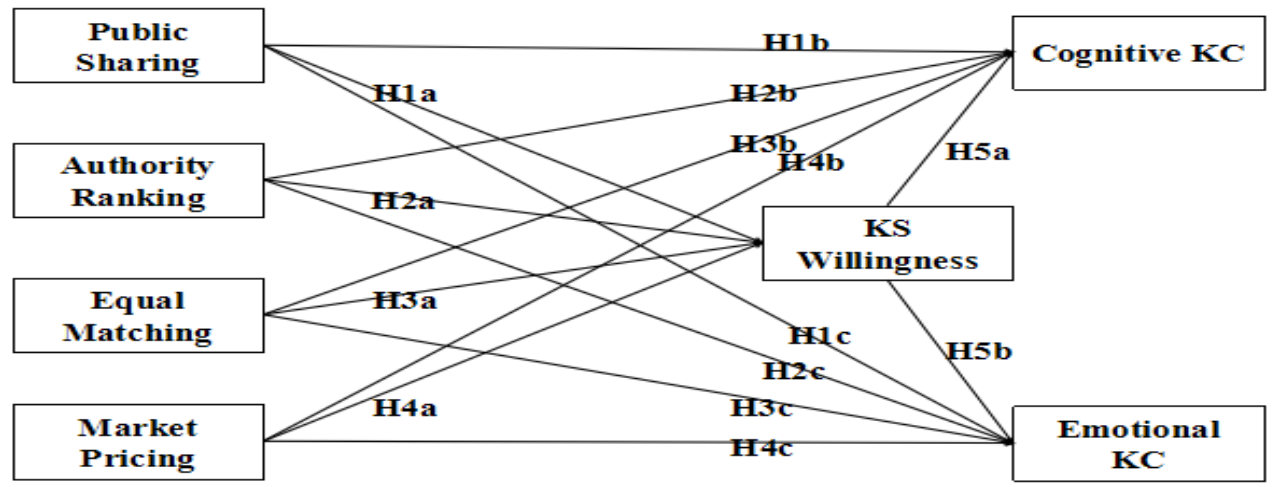

FIGURE 1. Research model of knowledge conflicts and relation model

\section{QUESTIONNAIRE INQUIRIES AND DATA ANALYSIS Descriptive Statistical Analysis}

The questionnaire survey was adopted for this research to collect data. The questionnaire mainly contained items related to social relations, knowledge conflicts and knowledge sharing. Likert scale five-level marking system was adopted and "complete disagreement" to "complete agreement" respectively represented 1 to 5 scores. In this questionnaire, the scale that had been used by predecessors for their research was referred for definitions of all variables and item design and it has been revised (Table 1).

The object of study for this paper was the scientific research teams in universities and therefore, high-level research-oriented universities that have been listed in Project 985 in China were taken as the research sample. Fourteen universities were selected for the formal questionnaire. From the regional distribution, 4 of them are located in the North China, two of them are located in the Northeast China, 4 of them are located in the Eastern China, two of them are located in the Mid-south Region and only one is respectively located in the Southwest China and Northwest China. Moreover, the scientific research teams whose members exceed 5 were taken as the object of the study, the number of team members in average was 9 and the research fields involved management science, physics, mathematics, sociology, psychology, computer science, traffic engineering and civil engineering, more than 10 majors in total. In the Eastern China, 80 pieces of questionnaires were issued and 72 pieces were taken back through the field research in four universities; in other regions, 380 pieces were issued through e-mails and 216 pieces were taken back. Those who signed the effective questionnaires included 22 professors, 39 associate professors, 45 lecturers, 87 doctoral students and 95 postgraduates. 301 questionnaires are taken back in total 
for this research with return rate for $65.4 \%$, among which, 13 surveys were rejected due to incomplete or unclear answers and the effective questionnaires were 288 pieces with effective rate for $95.7 \%$.

TABLE 1. Variables in the model

\begin{tabular}{|c|c|c|}
\hline Variables & Definition & Source \\
\hline Altruism & $\begin{array}{l}\text { The quality of unselfish concern for the welfare } \\
\text { of others. }\end{array}$ & Hung et al. (2011) \\
\hline Emotional Trust & $\begin{array}{l}\text { Trust that is built based on emotional } \\
\text { connection }\end{array}$ & Lewis \& Weigert (1985) \\
\hline Cognitive Trust & $\begin{array}{l}\text { Trust that is built based on approval and proper } \\
\text { reasons for trust }\end{array}$ & Lewis \& Weigert (1985) \\
\hline Academic Power & $\begin{array}{l}\text { The power of influence and intervention on } \\
\text { academic affairs and academic activities } \\
\text { according to experts and scholars' academic } \\
\text { level and academic ability. }\end{array}$ & $\operatorname{Li}(2011)$ \\
\hline Administrative Power & $\begin{array}{l}\text { A kind of ability of the administrations to carry } \\
\text { out the management of the departments in } \\
\text { universities }\end{array}$ & $\operatorname{Li}(2011)$ \\
\hline Power Distance & $\begin{array}{l}\text { The degree to which people accept hierarchical } \\
\text { authority and how far they are willing to } \\
\text { subordinate themselves }\end{array}$ & Farh, Hackett \& Liang (2007) \\
\hline Reciprocal & $\begin{array}{l}\text { A conditional exchange of interests and mutual } \\
\text { satisfaction }\end{array}$ & Hung et al. (2011) \\
\hline Expected Rewards & $\begin{array}{l}\text { Believe to gain rewards through knowledge } \\
\text { sharing behavior }\end{array}$ & Bock \& Kim (2002) \\
\hline Expected Association & $\begin{array}{l}\text { Believe to enhance connection with other } \\
\text { organizations through knowledge sharing } \\
\text { behavior }\end{array}$ & Bock \& Kim (2002) \\
\hline Tangible Rewards & $\begin{array}{l}\text { Believe to be offered higher salary or promotion } \\
\text { by achieving a goal }\end{array}$ & Lee et al. (1991) \\
\hline Costs & $\begin{array}{l}\text { Time and efforts spent during knowledge } \\
\text { sharing }\end{array}$ & Williamson (1996) \\
\hline KS Willingness & $\begin{array}{l}\text { Possibilities that one subjectively conducts } \\
\text { knowledge sharing }\end{array}$ & Ajzen (2002) \\
\hline
\end{tabular}

\section{Reliability and Validity Analysis}

SPSS21.0 statistical software was adopted for this research to conduct reliability and validity analysis of this questionnaire. For reliability, the internal consistency index was adopted to conduct the reliability testing on variables. The overall $\alpha$ factor of questions in this questionnaire reached 0.875 , and the inspection result of each variable in relation model was shown in Table 2; Cronbachs $\alpha$ factor of each variable exceeded 0.6, between 0.603 to 0.85 , which indicated that the data were acceptable. Validity was measured mainly through content validity and convergent validity. Except that the factor load of the fourth item's KSW related to the knowledge sharing willingness was 0.57 , the factor load of other observed factors exceeded 0.6; the average variable extraction values (AVE) of all variables exceeded 0.5 and all composite reliability (CR) values exceeded 0.7 , which indicated all variables had relatively good reliability. It overall indicated that reliability and validity of this questionnaire satisfied requirements.

\section{Establishment of Structural Equation Model}

Based on reliability and validity analysis, according to the conceptual model proposed above, AMOS20.0 software was adopted to construct the structural equation, 
including complete mediation model M1 and partial mediation model $\mathrm{M} 2$ and testing and comparison of adaptation degree were conducted after operation of these two models. In the complete mediation model M1, four kinds of social relations had indirect influence on knowledge conflicts only through the mediating effect of the knowledge sharing willingness; the direct effect channels of social relations on knowledge conflicts were added for the partial mediation model M2 based on the complete mediation model.

TABLE 2. Reliability and validity analysis of variables in relation model

\begin{tabular}{|c|c|c|c|c|c|c|}
\hline Measurement & & Items & Factor Loading & A & CR & AVE \\
\hline \multicolumn{7}{|l|}{ Variables } \\
\hline \multirow{7}{*}{$\begin{array}{l}\text { Public } \\
\text { Sharing }\end{array}$} & \multirow{5}{*}{ Trust } & $\mathrm{T} 1$ & 0.916 & \multirow{5}{*}{0.85} & \multirow{5}{*}{0.9029} & \multirow{5}{*}{0.7032} \\
\hline & & $\mathrm{T} 2$ & 0.894 & & & \\
\hline & & T3 & 0.634 & & & \\
\hline & & $\mathrm{T} 4$ & 0.879 & & & \\
\hline & & A1 & 0.667 & & & \\
\hline & \multirow[t]{2}{*}{ Altruism } & A2 & 0.754 & \multirow[t]{3}{*}{0.758} & \multirow[t]{3}{*}{0.7532} & \multirow[t]{3}{*}{0.5063} \\
\hline & & A3 & 0.711 & & & \\
\hline \multirow{7}{*}{ Authority Ranking } & \multirow{3}{*}{$\begin{array}{l}\text { Power } \\
\text { Distance }\end{array}$} & PD1 & 0.521 & & & \\
\hline & & PD2 & 0.848 & \multirow[t]{2}{*}{0.674} & \multirow[t]{2}{*}{0.7804} & \multirow{2}{*}{0.5521} \\
\hline & & PD3 & 0.816 & & & \\
\hline & & $\mathrm{P} 1$ & 0.797 & \multirow{4}{*}{0.817} & \multirow{4}{*}{0.8799} & \multirow{4}{*}{0.6468} \\
\hline & Power & $\mathrm{P} 2$ & 0.807 & & & \\
\hline & \multirow[t]{2}{*}{ Degree } & P3 & 0.809 & & & \\
\hline & & $\mathrm{P} 4$ & 0.804 & & & \\
\hline \multirow{8}{*}{$\begin{array}{l}\text { Equal } \\
\text { Matching }\end{array}$} & \multirow{3}{*}{$\begin{array}{l}\text { Expected } \\
\text { Rewards }\end{array}$} & ER1 & 0.808 & \multirow{3}{*}{0.643} & \multirow{3}{*}{0.8096} & \multirow{3}{*}{0.5872} \\
\hline & & ER2 & 0.783 & & & \\
\hline & & ER3 & 0.704 & & & \\
\hline & \multirow{5}{*}{$\begin{array}{l}\text { Expected } \\
\text { Association }\end{array}$} & EA1 & 0.893 & \multirow{5}{*}{0.718} & \multirow{5}{*}{0.85} & \multirow{5}{*}{0.535} \\
\hline & & EA2 & 0.717 & & & \\
\hline & & EA3 & 0.698 & & & \\
\hline & & EA4 & 0.697 & & & \\
\hline & & EA5 & 0.625 & & & \\
\hline \multirow{6}{*}{$\begin{array}{l}\text { Market } \\
\text { Pricing }\end{array}$} & \multirow{3}{*}{$\begin{array}{l}\text { Tangible } \\
\text { Rewards }\end{array}$} & TR1 & 0.835 & \multirow{3}{*}{0.724} & & \\
\hline & & TR2 & 0.748 & & 0.8442 & 0.6441 \\
\hline & & TR3 & 0.822 & & & \\
\hline & & Cost1 & 0.693 & & & \\
\hline & Costs & Cost2 & 0.733 & 0.603 & 0.7924 & 0.5611 \\
\hline & & Cost3 & 0.816 & & & \\
\hline
\end{tabular}

TABLE 3. Statistical results of model fitting

\begin{tabular}{lllllll}
\hline \hline & CMIN $/$ DF & GFI & AGFI & IFI & CFI & RMESA \\
\hline & & & & & & \\
M1 & 1.564 & 0.825 & 0.773 & 0.913 & 0.923 & 0.096 \\
M2 & 1.157 & 0.924 & 0.919 & 0.942 & 0.976 & 0.044 \\
Standards & $1-5$ & $>0.9$ & $>0.8$ & $>0.9$ & $>0.9$ & $<0.08$ \\
\hline \hline
\end{tabular}

The comprehensive evaluation result of model M1 all of which failed to reach the satisfactory requirements; indicated that its $\mathrm{GFI}=0.825, \mathrm{AGFI}=0.773$, $\mathrm{RMESA}=0.096$, the indexes of adaptation degree of the partial mediation 
model M2 all had reached the standard (see Table 3) and the external quality of this model was good. Therefore, the finally determined structural equation model was shown in Figure 2.

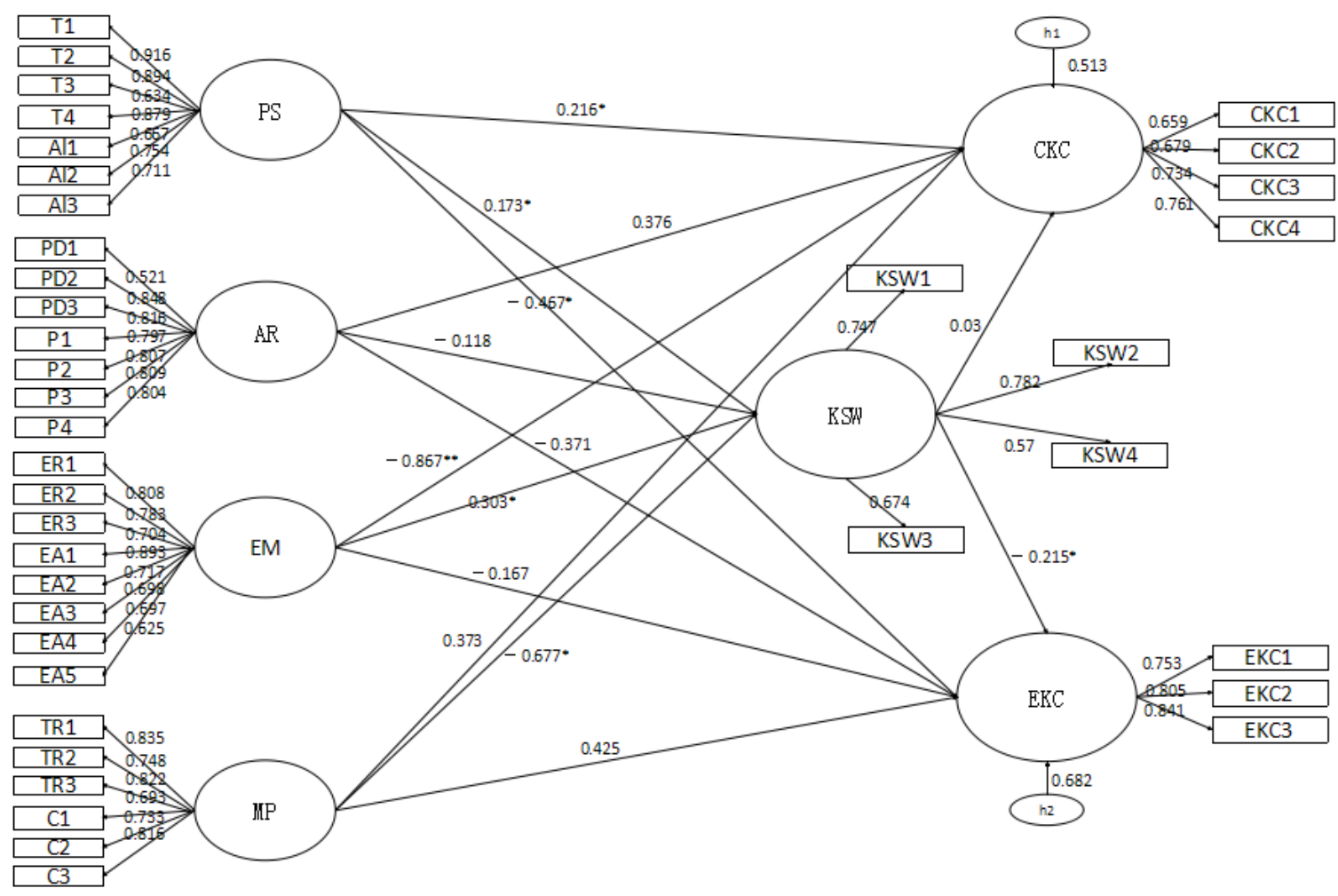

FIGURE 2. Model M2 and path analysis

\section{RESULTS AND DISCUSSION}

\section{Influence Effects of the Public Sharing Relation}

After operation of the structural equation model M2, the non-standard regression coefficient of the model and its significance testing result were achieved (Table 4). Table 4 showed that hypotheses of $\mathrm{H} 1 \mathrm{a}, \mathrm{H} 1 \mathrm{~b}$ and $\mathrm{H} 1 \mathrm{c}$ were correct. The public sharing is able to enhance the knowledge sharing willingness, stimulate deep knowledge communication among members and suppress their discontent and friction; and it may be said to be a kind of social relation that is beneficial to knowledge sharing and the innovation ability improvement for the scientific research team. Altruism under the public sharing relation is an individual' $s$ inherent characteristic and value, which is difficult to be changed through leaders' management methods, and the result also indicates that influence of trust on knowledge conflicts is more significant than that of altruism $(\mathrm{P}<0.01)$.

Therefore, in order to improve the knowledge sharing effect, the team leaders need to enhance the trust relationship among team members to enhance the team cohesiveness through constructing good team atmosphere and strengthening communication among members.

\section{Influence Effects of the Authority Ranking}

Results show that, the power distance has significant negative effect on the knowledge sharing willingness and influence of the power degree on the knowledge sharing willingness is minor. $\mathrm{H} 2 \mathrm{a}$ is correct partially, which indicates that the hierarchical difference inside a team will cause relatively huge barrier for members' knowledge sharing willingness; on the other hand, the power distance has no significant influence on knowledge conflicts, while the power degree has significant influence on cognitive knowledge conflicts and emotional conflicts. Therefore, hypotheses of $\mathrm{H} 2 \mathrm{~b}$ and $\mathrm{H} 2 \mathrm{c}$ are correct partially.

It is generally acknowledged that, excessively great power or legal force of the leader in a team is not beneficial to the team's harmony and will cause a barrier for its performance. However, considering power in a scientific research team is mainly the academic power, and it is generated due to multi-year academic credentials and 
influence of the team leader, it's a kind of optional power that makes members easy to trust. Therefore, the academic power in a scientific research team will not only enhance effects of knowledge sharing and knowledge communication, but also facilitate communication among team members to further reduce conflicts and improve the innovation performance. The team leader shall attach great importance to the positive guiding function of the academic authority and reasonably apply the academic power with open, encouraging and optional manner; meanwhile, make great efforts to shorten the power distance within the team.

TABLE 4. Non-standardized regression coefficient and its significance test results

\begin{tabular}{|c|c|c|c|c|c|c|c|c|}
\hline & $\begin{array}{l}\text { Dependent } \\
\text { Variables }\end{array}$ & & $\begin{array}{l}\text { Independent } \\
\text { Variables }\end{array}$ & Estimate & S.E. & C.R. & $\mathbf{P}$ & $\mathrm{Y} / \mathrm{N}$ \\
\hline \multirow{2}{*}{ H1a } & KSW & $<---$ & Trust & 0.14 & 0.043 & 3.28 & 0.001 & \multirow{2}{*}{ Y } \\
\hline & KSW & $<---$ & Altruism & 0.033 & 0.046 & 0.729 & 0.047 & \\
\hline \multirow{2}{*}{$\mathrm{H} 1 \mathrm{~b}$} & CKC & $<---$ & Trust & 0.1 & 0.047 & 2.112 & 0.035 & \multirow{2}{*}{ Y } \\
\hline & CKC & $<---$ & Altruism & 0.116 & 0.057 & 2.041 & 0.041 & \\
\hline \multirow{2}{*}{$\mathrm{H} 1 \mathrm{c}$} & EKC & $<---$ & Trust & -0.302 & 0.072 & -4.179 & $* * *$ & \multirow{2}{*}{ Y } \\
\hline & EKC & $<---$ & Altruism & -0.165 & 0.078 & -2.123 & 0.034 & \\
\hline \multirow{2}{*}{$\mathrm{H} 2 \mathrm{a}$} & KSW & $<---$ & PD & -0.139 & 0.048 & -2.867 & 0.004 & \multirow{2}{*}{ Partially } \\
\hline & KSW & $<---$ & Power & 0.021 & 0.061 & 0.347 & 0.729 & \\
\hline \multirow{2}{*}{$\mathrm{H} 2 \mathrm{~b}$} & CKC & $<---$ & Power & 0.236 & 0.061 & 3.858 & $* * *$ & \multirow{2}{*}{$\mathrm{N}$} \\
\hline & СКC & $<---$ & PD & 0.14 & 0.076 & 1.827 & 0.068 & \\
\hline \multirow{2}{*}{$\mathrm{H} 2 \mathrm{c}$} & EKC & $<---$ & PD & -0.017 & 0.075 & -0.229 & 0.819 & \multirow{2}{*}{ Partially } \\
\hline & EKC & $<---$ & Power & -0.354 & 0.112 & -3.151 & 0.002 & \\
\hline \multirow{2}{*}{ H3a } & KSW & $<---$ & ER & 0.102 & 0.035 & 2.909 & 0.004 & \multirow{2}{*}{ Y } \\
\hline & KSW & $<---$ & EA & 0.201 & 0.087 & 2.316 & 0.021 & \\
\hline \multirow{2}{*}{$\mathrm{H} 3 \mathrm{~b}$} & СКС & $<---$ & ER & -0.117 & 0.042 & -2.8 & 0.005 & \multirow{2}{*}{ Y } \\
\hline & СКC & $<---$ & EA & -0.75 & 0.155 & -4.827 & $* * *$ & \\
\hline \multirow{2}{*}{$\mathrm{H} 3 \mathrm{c}$} & EKC & $<---$ & ER & 0.04 & 0.055 & 0.733 & 0.463 & \multirow{2}{*}{ Partially } \\
\hline & EKC & $<---$ & EA & -0.171 & 0.246 & -5.564 & $* * *$ & \\
\hline \multirow{2}{*}{$\mathrm{H} 4 \mathrm{a}$} & KSW & $<--$ & $\mathrm{TR}$ & 0.131 & 0.057 & 2.302 & 0.021 & \multirow{2}{*}{ Y } \\
\hline & KSW & $<---$ & Cost & -0.808 & 0.259 & -4.282 & $* * *$ & \\
\hline \multirow{2}{*}{$\mathrm{H} 4 \mathrm{~b}$} & СКC & $<---$ & $\mathrm{TR}$ & 0.05 & 0.066 & 0.762 & 0.446 & \multirow{2}{*}{ Partially } \\
\hline & СКC & $<---$ & Cost & 0.323 & 0.125 & 2.587 & 0.01 & \\
\hline \multirow[b]{2}{*}{$\mathrm{H} 4 \mathrm{c}$} & EKC & $<---$ & $\mathrm{TR}$ & -0.107 & 0.091 & -1.177 & 0.239 & \multirow[b]{2}{*}{ Partially } \\
\hline & EKC & $<---$ & Cost & 0.632 & 0.194 & 3.262 & 0.001 & \\
\hline $\mathrm{H} 5 \mathrm{a}$ & $\mathrm{CKC}$ & $<---$ & KSW & 0.03 & 0.046 & 0.803 & 0.463 & \multirow[b]{2}{*}{ Partially } \\
\hline $\mathrm{H} 5 \mathrm{~b}$ & EKC & $<--$ & KSW & -0.215 & 0.063 & 1.214 & 0.034 & \\
\hline
\end{tabular}

\section{Influence Effects of Equal Matching}

The positive effect of the equal matching relation on the knowledge sharing willingness is significant at Level 0.5 , which indicates hypothesis of $\mathrm{H} 3 \mathrm{a}$ is correct. Except the minor influence of the expected rewards on the emotional conflicts, the equal matching relation has significant negative effect on two types of knowledge conflicts. Therefore, hypothesis of $\mathrm{H} 3 \mathrm{~b}$ is correct and hypothesis of $\mathrm{H} 3 \mathrm{c}$ is partially correct. Especially with respect to the expected association, it has significant influence on cognitive conflicts and emotional conflicts at Level 0.01. In recent years, with the accelerating openness and internationalization of the academic research, the domestic scientific research teams tend to expect to achieve higher-level research achievements through cooperation of trans-team, trans-discipline, transuniversity, and even transnational scientific research team, so the influence of the expected association on the knowledge sharing willingness and knowledge conflicts is more significant than that of the expected rewards. 


\section{Influence Effects of Market Pricing Relation}

The market pricing relation has significant influence on the knowledge sharing willingness and the hypothesis of $\mathrm{H} 4 \mathrm{a}$ is correct. The tangible rewards areable to enhance the knowledge sharing willingness significantly and the influence of costs on the knowledge sharing willingness is more significant than that of the tangible rewards $(\mathrm{P}<0.01)$. In addition, the influence of the tangible rewards on two kinds of knowledge conflicts is minor, while the positive effect of costs on conflicts is above Level 0.05, which means the influence is significant. Hypotheses of $\mathrm{H} 4 \mathrm{~b}$ and $\mathrm{H} 4 \mathrm{c}$ are partially correct.

Under the current marketization environment, more and more scientific research teams start to give awards on the knowledge innovation achievements in the economic manner; however, the direct monetary compensation on the knowledge sharing behavior is little. Because the intangible value and tangible benefits provided by the scientific research achievements for the individual is usually far more than the awards on the knowledge sharing, and appropriate return to the time and energy consumed on knowledge sharing is difficult to get, the knowledge sharing willingness of members is not intensive considering costs; however, due to the competition between the individual benefits within a team, knowledge conflicts are easy to be triggered.

In conclusion, knowledge sharing in a scientific research team is different from that in ordinary enterprise and the economic incentive shall not be taken as the primary method to improve the knowledge innovation capacity in a scientific research team. For a manager, he/she shall establish the knowledge sharing platform and environment to effectively reduce the share costs and overcome the share bottleneck.

\section{The Mediating Effect of Knowledge Sharing Willingness}

The knowledge sharing willingness has significant negative effect on the emotional knowledge conflicts and therefore, the hypothesis of H5b is correct. However, its positive effect on cognitive knowledge conflicts is minor and the hypothesis of $\mathrm{H} 5 \mathrm{a}$ is incorrect. Moreover, the knowledge sharing willingness has the mediating effect among the public sharing, equal matching and marketing pricing and emotional conflicts, in which, the knowledge sharing willingness only has partial mediating effect between the public sharing and emotional knowledge conflicts, the ratio of this mediating effect in the total effect is $0.173^{*}(-0.215 /(-0.467)=0.080$. However, the knowledge sharing willingness has complete mediating effect between the equal matching and emotional knowledge conflicts and its effect ratio is $0.303 *(-0.215)=$ -0.065 ; finally, the knowledge sharing willingness also has the complete mediating effect between the market pricing and emotional knowledge conflicts, and the ratio is ($0.677) *(-0.215)=0.146$.

It is generally recognized that, the knowledge sharing willingness is able to effectively strengthen the cooperation desire of team members, promote depth and breadth of knowledge communication, enhance cognitive knowledge conflicts, weaken emotional knowledge conflicts and finally improve the knowledge sharing performance of a team. Because the knowledge sharing willingness is a subjective feeling, the relation between knowledge sharing willingness and emotional conflicts is more significant. Meanwhile, under different social relations, the mediating adjustment effect of the knowledge sharing willingness is also different; especially under the equal matching relation and the market pricing relation, the knowledge sharing willingness has the complete mediating effect. From the above discussion, it is necessary to improve the knowledge sharing willingness of the members through aiming for members' fair psychology utility maximization and by cultivating open and friendly team atmosphere and constructing fair and effective knowledge communication platform, etc.

\section{CONCLUSION AND FUTURE STUDY}

Because the existing documents related to knowledge conflicts mainly focus on studying the relationship between knowledge conflicts and the team performance, and few reasons for occurrence of knowledge conflicts are considered, several divergent study conclusions are generated. In this paper, the view of studying is turned to the occurrence mechanism of knowledge conflicts and it aims to explore the influence factors of knowledge conflicts and explain their relationship. Through the empirical research and analysis, it is found that the public sharing relation is the most ideal social relation in a team, which has significant positive effect on cognitive knowledge conflicts and significant negative effect on emotional knowledge conflicts. Considering the effect of the academic power, there is certain difference with other teams in the influence of the authority ranking on the scientific research team, in which, the power degree has significant positive effect on knowledge conflicts. The equal matching relation has significant negative effect on cognitive conflicts and the cost share under the market 
pricing relation has significant positive effect on knowledge conflicts. In addition, the knowledge sharing willingness has mediating effect between the social relations and emotional conflicts. In this paper, the influence of the social relations on knowledge conflicts is studied, but it still has certain limitation. Other factors, such as psychology, educational background and race, which result in knowledge conflicts, can be taken into account in the future or refine the category of the project team to study the occurrence mechanism of knowledge conflicts and the coping strategies in the project teams with different task characteristics.

\section{Acknowledgment}

This research is supported by the National Nature Science Foundation of China (No. 71201073, 71390521).

\section{REFERENCES}

Ajzen, I. 2002. Perceived behavioral control self-efficacy locus of control and the theory of planned behavior. Journal of Applied Social Psychology, 32 (4): 665-683. DOI: 10.1111/j.1559-1816.2002.tb00236.x

Amason, A.C., \& Schweiger, D.M. 1994. Resolving the paradox of conflict strategic decision making and organizational performance.International Journal of Conflict Management, 5(3): 239-253. DOI: 10.1108/eb022745

Blau. P. 1964. Exchange and power in social life. New York, US: Wiley.

Bock, G.W., \& Kim, Y.G. 2002. Determinants of the individuals knowledge sharing behavior: The theory of reasoned action perspective. Paper presented at the Pasific-Asia Conference on Information System (pp. 1008-1023), Meiji University, Tokyo, Japan.

Boer, N.I., Berends, H., \& Van Baalen, P. 2011. Relational models for knowledge sharing behavior. European Management Journal, 29(2): 85-97. DOI: 10.1016/j.emj.2010.10.009

Davenport, T.H., \& Klahr, P. 1998. Managing customer support knowledge. California Management Review, 40(3): 195208. DOI: $10.2307 / 41165950$

Farh, J.L., Hackett, R.D., \& Liang, J. 2007. Individual-level cultural values as moderators of perceived organizational support-employee outcome relationships in China: Comparing the effects of power distance and traditionality. Academy of Management Journal, 50(3): 715-729. DOI: 10.5465/AMJ.2007.25530866

Fiske, A.P. 1992. The four elementary forms of sociality: Framework for a unified theory of social relations. Psychological Review, 99(4): 689-723. DOI: 10.1037/0033-295X.99.4.689

French, J.R., Raven, B., \& Cartwright, D. 1959. The bases of social power. In Classics of organization theory. Boston, MA: Wadsworth Cengage Learning.

Hung, S.Y., Durcikova, A., Lai, H.M., \& Lin, W.M. 2011. The influence of intrinsic and extrinsic motivation on individuals' knowledge sharing behavior. International Journal of Human-Computer Studies, 69(6): 415-427. D0I: 10.1016/j.ijhcs.2011.02.004

Joseph, B., \& Jacob, M. 2011. Knowledge sharing intentions among IT professionals in India. In S. Dua, S. Sahni, D. P. Goyal (Eds.), Information intelligence, systems, technology and management. Paper presented at the 5 th International Conference Proceedings Communications in Computer and Information Science (23-31). Gurgaon, India: Springer. DOI: $10.1007 / 978-3-642-19423-8 \_3$

Kurz, M. 1997. Altruism equilibrium. In B. Balassa \& R. Nelson (Eds.), Economic progress, private values, and public policy: Essays in honor of William Fellner. Amsterdam, ND: North-Holland Publishing Co.

Lee, C., Bobko, P., Christopher Earley, P., \& Locke, E.A. 1991. An empirical analysis of a goal setting questionnaire. Journal of Organizational Behavior, 12(6): 467-482. DOI: 10.1002/job.4030120602

Lewis, J.D., \& Weigert, A. 1985. Trust as a social reality. Social Forces, 63(4): 967-985. D0I: 10.2307/2578601

Li S. 2008. The Relation between powers in innovative team of university. Higher Education Research and Evaluation, 20(7):26-30.

Li X., Zhou H., \& Cai X. 2010. An Empirical study on the relationship between trust and knowledge-sharing in university research team. Library and Information Service, 54(10): 92-95.

Li, H. 2011. The Empirical research on current situation on academic power in university. Educational Research, (10): 49-53. 
Lin, H.F. 2007. Effects of extrinsic and intrinsic motivation on employee knowledge sharing intentions. Journal of Information Science, 33(2): 135-149. DOI: 10.1177/0165551506068174

Lin, T.C., Wu, S., \& Lu, C.T. 2012. Exploring the affect factors of knowledge sharing behavior: The relations model theory perspective. Expert Systems with Applications, 39(1): 751-764. DOI: 10.1016/j.eswa.2011.07.068

Nonaka, I., Toyama, R., \& Konno, N. 2000. SECI, Ba and leadership: A unified model of dynamic knowledge creation. Long Range Planning, 33(1): 5-34. DOI: 10.1016/S0024-6301(99)00115-6

Tan, C.W., Pan, S.L., Lim, E.T.K., \& Chan, C.M.L. 2005. Managing knowledge conflicts in an interorganizational project: A case study of the infocomm development authority of Singapore. Journal of the American Society for Information Science and Technology, 56(11): 1187-1199. D0I: 10.1002/asi.20222

Tang, L.I. 2000. Research of the network of knowledge sharing. Unpublished doctoral dissertation, National Cheng-Chi University, Taiwan.

Wei H., \& Long L. 2011. The effect of cognition and affect-based trust power distance and system control on leader empowering behavior. Journal of Industrial Engineering/Engineering Management, 25(1): 10-16.

Williamson, O.E. 1996. Economic organization: The case for Candor. Academy Management Review, 21 (1): 48-57. D0I: $10.2307 / 258628$

Yin, H. 2012. Research on the impact of knowledge conflict of team on radical innovation performance of enterprises. Science and Technology Progress and Policy, 29(16): 120-125.

Zhang, G., \& Fang L. 2007. Knowledge conflicts and team performance: An empirical study. Scientific Research Management, 28(6): 12-21.

— This article does not have any appendix. - 